\title{
Intergenerational equity and responsibility: a call to internalize impermanence into certifying carbon sequestration
}

\author{
Stephanie H. Arcusa ${ }^{1 *}$, Klaus S. Lackner ${ }^{2}$ \\ ${ }^{1}$ Center for Negative Carbon Emissions, Global Futures Laboratory, Arizona University, Tempe, \\ Arizona, USA \\ ${ }^{2}$ Center for Negative Carbon Emissions, School of Sustainable Engineering \& the Built Environment, \\ Arizona State University, Tempe, Arizona, USA \\ * Correspondence: \\ Stephanie Arcusa \\ sarcusa@asu.edu
}

Keywords: Carbon Dioxide Removal, carbon sequestration, certificates of carbon sequestration, Negative Emission Technology, certification, intergenerational equity, responsibility, permanence

\begin{abstract}
Carbon Dioxide Removal that limits or reduces cumulative emissions for the goal of climate action requires sequestration. The assurance that carbon remains sequestered is colloquially known as permanence. In current certification frameworks, permanence is often ascribed a duration inconsistent with and much shorter than the scientific understanding of the lifetime of carbon in the environment. These frameworks treat "impermanence" as an externality. First, this violates the polluter-pays principle rooted in international law, as it absolves the emitter and storage operator of responsibility. Second, any failure of sequestration threatens intergenerational equity, which is a binding concept in climate treaties. Impermanence can be managed if the responsibility for future losses is clearly delineated. For responsible carbon management, we propose shifting the responsibility for the carbon onto the storage operator. As a result the cost monitoring the carbon reservoir and re-sequestration of any losses will have to be incorporated into the cost of certificates of carbon sequestration. Internalizing monitoring and re-sequestration put temporary and long-term storage on equivalent footing and allow for both. It therefore would strengthen the likelihood of success in reaching the climate goal and would help bridge a major gap between typically short-lived "natural" solutions and theoretically long-lived "engineered" solutions without compromising intergenerational equity.
\end{abstract}

\section{Introduction}

Carbon Dioxide Removal (CDR) will likely play an important role in reaching carbon neutrality and be necessary for reducing atmospheric $\mathrm{CO}_{2}$ concentrations (IPCC, 2018). In market and regulated systems, CDR must be certified by some means resulting in instruments known as certificates, credits, tokens, or units. Such instruments have been purchased as offsets to cancel present and historic emissions. As nations and organizations pledge carbon neutrality (UNFCCC Race to Zero ${ }^{1}$ ),

\footnotetext{
${ }^{1} \mathrm{https}: / /$ racetozero.unfccc.int/
} 
demand for CDR is poised to increase (Turner et al., 2021), and so should scrutiny on how the certification process is designed (Miltenberger et al., 2021).

A primary concern is how long sequestration of excess carbon must last through time (Cox et al., 2018; Wong, 2014). For sequestration to be useful, carbon must remain sequestered long enough that the sum of all future carbon releases has no significant impact on the environment. For warming this would require sequestration over millennia to match deep ocean uptake (Archer et al., 1998; Kheshgi et al., 2005). If preventing ocean acidification is also important, then sequestration must continue for 10,000-100,000 years to match the timescale of geological processes (Archer et al., 1998; 2009; Lackner, 2003; Scott et al., 2015). In our assessment, potential damages from ocean acidification, for example to coral reef ecosystems (Hoegh-Guldberg et al., 2017), are sufficient to warrant sequestration on this longer time scale.

The assurance that carbon remains sequestered is colloquially known as permanence. For geological storage the ISO defines long-term as "the minimum period necessary for geological $\mathrm{CO}_{2}$ storage to be considered an effective and environmentally safe climate change mitigation option" (ISO 27914:2017). We broaden this definition to all forms of sequestration. A storage reservoir can be considered permanent if the probability weighted damage (risk) of full or partial reversal during the required sequestration duration falls below the threshold of concern. Both the required sequestration duration and the threshold of concern are conventions that policy will have to define.

Carbon reservoir types fall along a spectrum from low reversal risk and high durability approaching or exceeding "permanence" (e.g., carbonate mineralization and deep geologic sequestration) to high reversal risk and low durability (e.g., forests, soils, and wooden products), with others falling in between (e.g., ocean disposal, biochar) (Lackner et al., 1995; IPCC, 2005; Minx et al., 2018; NASEM, 2019). Certain reservoir types with low reversal risks will likely achieve the goal of permanent sequestration after analysis and observation of the reservoir's specifics. However, most carbon sequestration available today, as evidenced by Microsoft and Stripe purchases, has low durability and high reversal risk (Joppa et al., 2021). Therefore, we consider most sequestration on offer today as lacking permanency.

In certification standards, permanence tends to be ascribed a value of 30-100 years (Miltenberger et al., 2021). This is inconsistent with the scientific understanding of how long sequestration will need to be maintained either for temperature- or acidification-damage control. The failure of sequestration to be permanent and maintained on the timescales described above goes against the polluter-pays principle and the intergenerational equity (Khan, 2015; Vaughan and Lenton, 2011; Wong, 2014; Scott et al., 2015). The polluter-pays principle has been adopted by the OECD (OECD, 1975), but not the UNFCCC (UN General Assembly, 1992; Khan, 2015).

Intergenerational equity is a binding principle recognized by international environmental agreements, including the Paris Agreement, of fair utilization of resources between generations supporting the sustainable development goals (UN General Assembly, 1972; 1992; Maggio, 1997; Paris Agreement, 2015). Short duration sequestration violates this principle. In a world where gigatons of carbon are sequestered for only 100 years, future generations would face increasing concentrations of atmospheric $\mathrm{CO}_{2}$. They would have to recapture carbon and re-sequester it, or adapt to rising temperatures. If economies shrink (Raffensperger, 2013), for example because of climate change (SwissRe Institute, 2021), future generations may be ill prepared to deal with this problem. 
Such future releases are a form of the "termination effect" usually reserved for solar radiation management to describe the potential for abrupt consequences should management end (Royal Society, 2009). The termination of sequestration would expose future generations to the full environmental impact of the released carbon (Keller et al., 2014). As discussed by Brandão et al., (2013), the known but unmanaged risk of a future carbon release violates intergenerational equity. Of course, intergenerational inequity is additional to other forms of inequity produced by climate change policies that have failed to reduce emissions sufficiently (Olhoff and Christensen, 2020). Temporary sequestration has value. It rectifies some inequity for present generations, and may lessen the potential of crossing tipping points (Dornburg and Marland, 2008; Herzog et al., 2003; Marland et al., 2001), as long as the responsibility to future generations is recognized by an obligation to resequestration.

Both principles must be considered in carbon sequestration policymaking. Yet, impermanence need not be an issue if appropriately managed. Here we review current certification policy and its relation to intergenerational responsibility. We propose a mechanism so temporary storage can be used to accelerate the response to excess carbon in the environment and provide a valuable addition to option portfolios without eliminating the polluter's long-term obligation.

\section{Intergenerational responsibility in existing frameworks}

The value, accounting, and solutions to temporary sequestration are discussed in detail (Brandão et al., 2013; Fearnside et al., 2000; Feng et al., 2002; Herzog et al., 2003; Levasseur et al., 2012; Moura Costa and Wilson, 2000), in particular for forest sequestration (Kim et al., 2008; Maréchal and Hecq, 2006; Newell and Stavins, 2000; Richards, 2004; Sohngen and Mendelsohn, 2003). When considering responsibility, two types of carbon sequestration certification frameworks are in use globally: "temporary crediting" and "permanent crediting with fixed liability" (Brander et al., 2021).

Temporary or "expiring" crediting (Maréchal and Hecq, 2006) was adopted for afforestation and reforestation projects under the Clean Development Mechanism (CDM) by the UNFCCC. Projects generated credits valid for a period, after which they had to be replaced by the emitter either with new temporary credits or long-term (non-sequestration) credits (UNFCCC, 2005). The re-purchasing requirement provided a mechanism for long-term sequestration and thus intergenerational responsibility. Yet temporary credits fell below expectations. Compared to credits labelled permanent, temporary credits appeared to be non-fungible because they expired, which depressed demand and prices (Neeff and Ascui, 2009). In essence, emitters did not want to re-purchase credits.

An alternative framework has since been favored called "permanent crediting with fixed liability and/or buffers" (Brander et al., 2021). An emitter purchases carbon storage in exchange for a storage operator taking their liability for a period determined by the standard developer. The operator is liable to remediate releases e.g., accidental failure, during the contractual period. Alternatively or in addition, buffers are applied to contain that risk. When the contract ends, the storage operator is no longer responsible. Under this framework, both emitter and storage operator are eventually free of responsibility. This allows emitters to purchase credits once and make indefinite claims of emission cancelation even though some or all the carbon may be released after the contract ends. The risk is transferred to the public. "Permanent crediting" is often a misnomer, as the framework does not include a mechanism for long-lived storage.

Some permitting schemes consider long-term responsibility. For example, post-contract liability transfer to a willing party with upfront compensation is implemented in some mandatory 
government-regulated markets. The European Union's Carbon Capture and Storage Directive includes a liability transfer to the member state once the storage operator proves $\mathrm{CO}_{2}$ is stored "indefinitely" (Haan-Kamminga, 2012). However, most voluntary markets do not include such transfers.

Under variations of the two frameworks described above, certification has been provided and associated instruments sold globally (World Bank Group, 2020). For example, Microsoft and Stripe received proposals for carbon sequestration totaling 142 million tons of $\mathrm{CO}_{2}\left(\right.$ Carbon Plan dataset $\left.{ }^{2}\right)$. Proposals included a mixture of sequestration systems, each with different stipulated sequestration durations. Our investigation filtered out proposals of avoided emission, and plots the amount of carbon sequestered that is still covered by the proposer's stated duration as function of the years passed (Figure 1). After 30 years there will be no responsible party assuring the continuation for $50 \%$ of sequestration. In other words, the burden of continuing sequestration will fall on a future public either as damages or additional cleanup and monitoring costs.

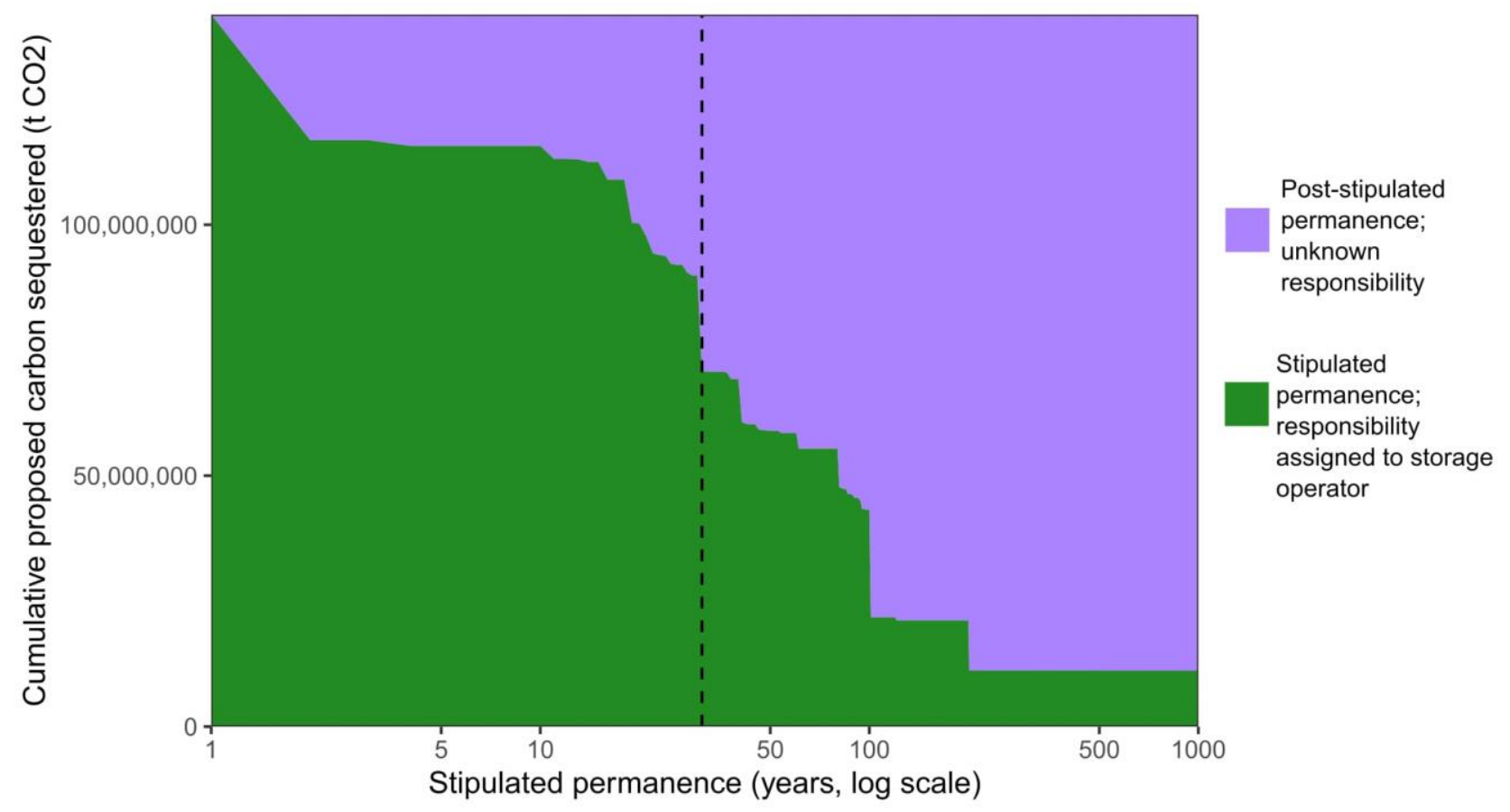

Figure 1. Cumulative sequestered carbon based on stipulated permanence from proposals received by Stripe and Microsoft in 2020 and 2021, excluding proposals of emission avoidance. The storage operator takes responsibility for the carbon during the contracted period. When the contract ends in the post-contract phase, the party responsible for any lost carbon is unknown under the existing certification frameworks. After just 30 years, nobody would be responsible for $50 \%$ of the carbon stored (dashed line), or the polluter should be made to purchase again. Data from CarbonPlan. (https://carbonplan.org/research/cdr-database).

${ }^{2}$ Data available at https://carbonplan.org/research/cdr-database 
We propose to account for carbon sequestration through a certification mechanism where a certificate of sequestration warrants a measured amount of carbon has been put in storage and that the liability for keeping this carbon stored lies with the storage operator. By purchasing certificates the emitter transfers the responsibility for the carbon to the storage operator and thus satisfies the polluter-pays principle. By taking on the long-term liability of re-sequestration in case the carbon escapes, the storage operator assures intergenerational equity.

\subsection{Assumptions}

Certificates can be issued when conditions are met as outlined in a standardized protocol. Conditions may be technical, like how carbon is measured, whereas others may be imposed on the storage operator like sourcing materials sustainably. We assume a method exists to quantify carbon in a specific reservoir type as well as any additions or losses and that these changes can be measured and certified by an independent party. Novel reservoirs may need dedicated research and development to create acceptable measurement protocols to produce certificates associated with these reservoirs. As technology advances, the range of reservoirs that can be used for generating certificates will broaden. We emphasize that measurements are a storage operator's basic obligation: a certificate must be backed with evidence, as "hollow" certificates amount to fraud. Allowing claims to storage that cannot be verified will destroy the credibility of all storage.

\subsection{Monitor and re-sequester}

The polluter-pays principle and intergenerational equity require that certificates internalize the potential reversal of sequestration. We propose the storage operator must bear the cost of required monitoring the carbon reservoir and potential re-sequestration and may have to demonstrate the ability to do so (e.g., through bonding, Gerard and Wilson, 2009). The storage operator would be responsible for a reasonable number of measurements with the frequency following a flexible model (e.g., Sleipner, Furre et al., 2017) determined by the specific risk associated with a particular reservoir type. A reservoir may eventually be considered permanent, for example after some trial period, where the reservoir is monitored and leakage rates calculated, but the specifics of this permanence test depend on the reservoir type and would need to be explored in each case. For example, if a geological formation where direct injection is implemented behaves as planned, the reservoir monitoring frequency could decrease and eventually end. Once a reservoir is considered permanent, the responsibility of the storage operator is deemed to be satisfied.

If monitoring finds a carbon loss from a reservoir, re-sequestration of an amount of carbon equivalent to what has been lost will be required. The storage operator's liability for re-sequestration can be satisfied by purchasing certificates of sequestration in the market. Re-sequestration could occur within the same sequestration type or by different means immediately after the release has been detected. For example, a storage operator confronted with a burned-down forest could re-sequester in a geologic reservoir. The re-sequestration requirement is not punitive, it simply backs up the original promise of continuous carbon storage.

\section{Discussion}

\subsection{Limitations and implications}


The proposal has limitations. It is not designed for other greenhouse gases such as methane that operate on different timescales and have different impacts and constraints (Lackner et al., 2000; Lackner, 2020). The proposal is not designed to confront other types of equity issues like those that are geographical (Carton et al., 2021), e.g., land grabs in other nations (ActionAid, 2015). If implemented as a market solution, this proposal could become monopolized or gamed. The proposal is silent on these issues. It highlights that intergenerational equity and the polluter's responsibility are currently not fully addressed. It provides a framework to address them.

Internalizing permanence will increase the price of most instruments for carbon removal because it demands that the principles of intergenerational equity and the polluter-pays are satisfied. This will result in new cost structures in ways that still need to be discovered. For some CDR, monitoring and re-sequestration costs could be significant due to inherent difficulties, but the proposed certificates would internalize accounting difficulties and the loss of carbon from storage uniformly across all methods. Virtually permanent storage options involving geological storage and/or mineralization appear to have sufficient capacity (IPCC, 2005; Lackner, 2002; Lackner et al., 1995) for even extreme sequestration scenarios putting an upper limit on the cost of sequestration. Insisting on the polluter-pays principle and intergenerational equity does not preclude access to sequestration. Furthermore, to the extent that the emission to be eliminated has not happened yet, there is nothing that would prevent the avoidance of fossil carbon. The higher price of carbon sequestration would likely motivate a more aggressive path toward non-fossil energy options.

The governance of maintaining carbon in an sequence of temporary storage sites, is extremely challenging (Ingelson et al., 2010; Ruseva et al., 2020). This suggests a natural transition to permanent storage where no future liability remains. Otherwise, there remains a maintenance requirement for future generations (Wong, 2014), even though the maintenance cost has already been included in the certificate's price. Our approach of demanding upfront payment for the responsibility to monitor and re-sequester offers a solution that shares the burden more fairly, one option to the question of who is responsible (Lawford-Smith \& Currie, 2017; Wong, 2014).

\subsection{Comparison to other options}

The proposed concept differs from those that discount short-term storage using ton-years (Chomitz, 2000; Fearnside et al., 2000; Kirschbaum, 2006; Moura Costa and Wilson, 2000) and those that use "buffers" to hold crediting to cover for reversals occurring within the contract time (Broekhoff et al., 2019). Discounting sanctions the inequity of leaving problems for future generations. Comparison with other hazards make this clear. Discounting a finite lifetime for radioactive storage is not acceptable, although even severe damages in a thousand years from now would not impact today's costs significantly. More generally, if an entity owns a hazardous waste site, they are responsible for that waste until the risk dissipates. The waste's responsibility is tied to the land's ownership where the waste is disposed. Buffers, meanwhile, should not be considered as instruments that deliver safeguards against the failure of storage to be permanent. They can compensate for accidental release during the contract time and may slightly extend the effective storage life time, but they do not uphold intergenerational equity. By requiring monitoring and re-sequestration, our approach achieves the same outcome of safeguarding from reversals during the contract time but also extends beyond it.

At the level discussed here, the proposed concept is agnostic to the sequestration option, even though each reservoir type will need its own implementation. A certificate's value is independent of the reservoir type, and each certificate offers the same service. By contrast, subsidies and taxes proposed for regulated forest sequestration that can result in trees never being harvested (van Kooten et al., 
1995 ) is favoring one technology over others. All sequestration needs to internalize impermanence. However, certificates could be complementary to a tax/subsidy system, with tax credits offered for policy-preferred options.

Our proposal complements the two-pronged strategy of increasing the global proportion of sequestered carbon and storage duration through time (Allen et al., 2020, 2009). The strategy is incorporated into the Oxford Principles for Net Zero Aligned Carbon Offsetting and the Carbon Takeback Obligation $\left(\mathrm{CBTO}^{3}\right)$. The former suggests phasing out offsets of emission reduction and of short-lived storage in favor of long-lived emission removal (Allen et al., 2020). The latter requires storing one tonne of $\mathrm{CO}_{2}$ for every tonne generated by burning fossil fuels (Allen et al., 2009). The CBTO requires storing $\mathrm{CO}_{2}$ only in geological storage rather than other storage types, suggesting it is safer, longer lasting, and less harmful to humans and the environment. However, we suggest to be technology and reservoir agnostic and propose a mechanism to do so, arguing short-lived storage does have an important role to play.

Temporary storage including reforestation, soil carbon enhancement, and ecosystem restoration are thought to be able to save $10 \mathrm{Gt} \mathrm{CO}$ e/yr by 2050 (Girardin et al., 2021) and are some of the more mature options available today (Griscom et al., 2017). We propose temporary removal would be designed with longevity in mind, by compensating operators for internalizing costs of monitoring and re-sequestration to also protect future generations.

\section{Concluding thoughts}

At a minimum, responsible carbon sequestration means meeting a science-based definition of permanence, internalizing the cost re-sequestration, and providing evidence of continued sequestration. Short-lived sequestration can be a bridge to permanent sequestration if it is not pursued at future generations' expense. Our proposal accomplishes this by integrating carbon reservoir monitoring and re-sequestration into a certification framework that delivers permanency even if the initial storage is impermanent. Internalizing the cost of impermanence makes it possible for temporary and permanent storage options to compete in the market on equal footing or to be treated equivalently in policy. Obligations incurred through the initial use of temporary storage will send a market signal for developing more permanent storage capacity. Our approach allows the emitter to transfer the responsibility for the carbon to the storage operator while satisfying the polluter-pays principle. It guarantees long-term ("permanent") sequestration and minimizes the burden on future generations. Demanding permanence will raise the cost of most temporary sequestration options. Technology advances and market forces will determine by how much costs will change. The price for ignoring these costs now, is that once it has become politically acceptable to discount the future, this approach will be too entrenched in society to reverse. Today insisting on permanence is justified by two principles, the polluter-pays and intergenerational justice. When sequestration fails in the future, there is no recourse to the polluter-pays principle. As more nations and corporations pledge carbon neutrality with heavy reliance on carbon sequestration, it is time to get certification of sequestration right and consider future generations' well-being too.

\section{Conflict of Interest}

K. Lackner is a coinventor of IP owned by Arizona State University (ASU) that relates to certain implementations of direct air capture. Dr. Lackner also consults for companies that work on direct air

\footnotetext{
${ }^{3}$ https://carbontakeback.org/
} 
capture. ASU has licensed part of its IP to Carbon Collect and owns a stake in the new company. As an employee of the University, Lackner is a technical advisor to the company and in recognition also received shares from the company. Carbon Collect also supports DAC research at ASU.

\section{$7 \quad$ Author Contributions}

K. Lackner conceived of the idea of monitoring and re-sequestration. S. Arcusa developed the idea of intergenerational equity. S. Arcusa wrote the text, performed the analysis, and created the figure. K. Lackner edited and SHA revised the text.

\section{$8 \quad$ Funding}

S. Arcusa gratefully acknowledges research funding from Conservation International and Arizona State University. K. Lackner gratefully acknowledges support from The Global KAITEKI Center at ASU, a university-industry partnership between ASU and The KAITEKI Institute of Mitsubishi Chemical Holdings Corporation.

\section{Acknowledgments}

We would like to thank Starry Sprenkle-Hyppolite for constructive feedback on the first version and the members of the Center for Negative Carbon Emissions for their support.

\section{Reference}

ActionAid, 2015. Caught in the net: How "net-zero emissions" will delay real climate action and drive land grabs. June 20153.

Allen, M., Axelsson, K., Caldecott, B., Hale, T., Hepburn, C., Hickey, C., Mitchell-Larson, E., Malhi, Y., Otto, F., Seddon, N., Smith, S., 2020. The Oxford Principles for Net Zero Aligned Carbon Offsetting September 202015.

Allen, M.R., Frame, D.J., Mason, C.F., 2009. The case for mandatory sequestration. Nat. Geosci. 2, 813-814. doi:10.1038/ngeo709

Archer, D., Eby, M., Brovkin, V., Ridgwell, A., Cao, L., Mikolajewicz, U., Caldeira, K., Matsumoto, K., Munhoven, G., Montenegro, A., Tokos, K., 2009. Atmospheric lifetime of fossil-fuel carbon dioxide. Annu. Rev. Earth Planet. Sci. 37.

Archer, D., Kheshgi, H., Maier-Reimer, E., 1998. Dynamics of fossil fuel CO2 neutralization by marine CaCO3. Global Biogeochem. Cycles 12, 259-276. doi:10.1029/98GB00744

Brandão, M., Levasseur, A., Kirschbaum, M.U., Weidema, B.P., Cowie, A.L., Jørgensen, S.V., Hauschild, M.Z., Pennington, D.W. and Chomkhamsri, K., 2013. Key issues and options in accounting for carbon sequestration and temporary storage in life cycle assessment and carbon footprinting. The International Journal of Life Cycle Assessment, 18(1), 230-240. doi:

$10.1007 / \mathrm{s} 11367-012-0451-6$

Brander, M., Ascui, F., Scott, V., Tett, S., 2021. Carbon accounting for negative emissions technologies. Clim. Policy 25, 1-19. doi:10.1080/14693062.2021.1878009 
Broekhoff, D., Gillenwater, M., Colbert-Sangree, T., Cage, P., 2019. Securing Climate Benefit: A Guide to Using Carbon Offsets.

Carton, W., Lund, J.F., Dooley, K., 2021. Undoing Equivalence: Rethinking Carbon Accounting for Just Carbon Removal. Front. Clim. 3, 1-7. doi:10.3389/fclim.2021.664130

Chomitz, K.M., 2000. Evaluating carbon offsets from forestry and energy projects: How do they compare? Energy 40, 1-22.

Cox, E.M., Pidgeon, N., Spence, E., Thomas, G., 2018. Blurred lines: The ethics and policy of Greenhouse Gas Removal at scale. Front. Environ. Sci. 6, 1-7. doi:10.3389/fenvs.2018.00038

Dornburg, V., Marland, G., 2008. Temporary storage of carbon in the biosphere does have value for climate change mitigation: A response to the paper by Miko Kirschbaum. Mitig. Adapt. Strateg. Glob. Chang. 13, 211-217. doi:10.1007/s11027-007-9113-6

Fearnside, P.M., Lashof, D.A., Moura-costa, P., 2000. Accounting for time in mitigating global warming through land-use change and forestry. Mitig. Adapt. Strateg. Glob. Chang. 5, 239-270.

Feng, H., Zhao, J., Kling, C.L., 2002. The time path and implementation of carbon sequestration. Am. J. Agric. Econ. 84, 134-149. doi:10.1093/ajae/84.1.134

Furre, A.K., Eiken, O., Alnes, H., Vevatne, J.N., Kiær, A.F., 2017. 20 Years of Monitoring CO2injection at Sleipner. Energy Procedia 114, 3916-3926. doi:10.1016/j.egypro.2017.03.1523

Gerard, D., Wilson, E.J., 2009. Environmental bonds and the challenge of long-term carbon sequestration. J. Environ. Manage. 90, 1097-1105. doi:10.1016/j.jenvman.2008.04.005

Girardin, C.A.J., Jenkins, S., Seddon, N., Allen, M., Lewis, S.L., Wheeler, C.E., Griscom, B.W., Malhi, Y., 2021. Nature-based solutions can help cool the planet — if we act now. Nat. Comment 593, 191-194.

Griscom, B.W., Adams, J., Ellis, P.W., Houghton, R.A., Lomax, G., Miteva, D.A., Schlesinger, W.H., Shoch, D., Siikamäki, J. V., Smith, P., Woodbury, P., Zganjar, C., Blackman, A., Campari, J., Conant, R.T., Delgado, C., Elias, P., Gopalakrishna, T., Hamsik, M.R., Herrero, M., Kiesecker, J., Landis, E., Laestadius, L., Leavitt, S.M., Minnemeyer, S., Polasky, S., Potapov, P., Putz, F.E., Sanderman, J., Silvius, M., Wollenberg, E., Fargione, J., 2017. Natural climate solutions. Proc. Natl. Acad. Sci. U. S. A. 114, 11645-11650. doi:10.1073/pnas.1710465114

Haan-Kamminga, A., 2012. Long Term Liability for Geological Storage in the European Union. SSRN Electron. J. doi:10.2139/ssrn.1858631

Herzog, H., Caldeira, K., Reilly, J., 2003. An issue of permanence: Assessing the effectiveness of temporary carbon storage. Clim. Change 59, 293-310. doi:10.1023/A:1024801618900

Hoegh-Guldberg, O., Poloczanska, E.S., Skirving, W., Dove, S., 2017. Coral reef ecosystems under climate change and ocean acidification. Front. Mar. Sci. 4. doi:10.3389/fmars.2017.00158 
Ingelson, A., Kleffner, A., Nielson, N., 2010. Long-Term Liability for Carbon Capture and Storage in Depleted North American Oil and Gas Reservoirs - a Comparative Analysis. Energy Law J. 31, 431469.

ISO (2017). Carbon dioxide capture, transportation, and geological storage - Geological storage. ISO Standard 27914. https://www.iso.org/standard/64148.html.

IPCC (2018). Summary for Policymakers. Global Warming of $1.5^{\circ} \mathrm{C}$. An IPCC Special Report on the impacts of global warming of $1.5^{\circ} \mathrm{C}$ above pre-industrial levels and related global greenhouse gas emission pathways, in the context of strengthening the global response to the threat of climate change, sustainable development, and efforts to eradicate poverty [Masson-Delmotte, V., P. Zhai, H.O. Pörtner, D. Roberts, J. Skea, P.R. Shukla, A. Pirani, W. Moufouma-Okia, C. Péan, R. Pidcock, S. Connors, J.B.R. Matthews, Y. Chen, X. Zhou, M.I. Gomis, E. Lonnoy, T. Maycock, M. Tignor, and T. Waterfield (eds.)]. In Press.

IPCC, 2005. IPCC Special Report on Carbon Dioxide Capture and Storage. Prepared by Working Group III of the Intergovernmental Panel on Climate Change. Cambridge University Press, Cambridge, United Kingdom and NewYork, NY, USA.

Joppa, L., Luers, A., Willmott, E., Friedmann, S.J., Hamburg, S.P., Broze, R., 2021. Microsoft's million-tonne CO2-removal purchase - lessons for net zero. Nature 597, 629-632.

Keller, D.P., Feng, E.Y. and Oschlies, A., 2014. Potential climate engineering effectiveness and side effects during a high carbon dioxide-emission scenario. Nature communications, 5(1), 1-11. doi: $10.1038 /$ ncomms4304

Khan, M., 2015. Polluter-Pays-Principle: The Cardinal Instrument for Addressing Climate Change. Laws 4, 638-653. doi:10.3390/laws4030638

Kheshgi, H.S., Smith, S.J., Edmonds, J.A., 2005. Emissions and atmospheric CO2 stabilization: Long-term limits and paths. Mitig. Adapt. Strateg. Glob. Chang. 10, 213-220. doi:10.1007/s11027005-3783-8

Kim, M.K., McCarl, B.A. and Murray, B.C., 2008. Permanence discounting for land-based carbon sequestration. Ecological Economics, 64(4), 763-769. doi: 10.1016/j.ecolecon.2007.04.013

Kirschbaum, M.U.F., 2006. Temporary carbon sequestration cannot prevent climate change. Mitig. Adapt. Strateg. Glob. Chang. 11, 1151-1164. doi:10.1007/s11027-006-9027-8

Kooten van, G.C., Binkley, C.S. and Delcourt, G., 1995. Effect of carbon taxes and subsidies on optimal forest rotation age and supply of carbon services. American journal of agricultural economics, 77(2), pp.365-374.

Lackner, K.S., 2020. Practical constraints on atmospheric methane removal. Nat. Sustain. 3, 357. doi:10.1038/s41893-020-0496-7

Lackner, K.S., 2003. A Guide to $\mathrm{CO}_{2}$ Sequestration. Science, 300, 1677-1678.

Lackner, K.S., 2002. Carbonate chemistry for sequestering fossil carbon. Annu. Rev. Energy Environ. 27, 193-232. doi:10.1146/annurev.energy.27.122001.083433 
Lackner, K.S., Wendt, C.H., Butt, D.P., Joyce, E.L., Sharp, D.H., 1995. Carbon dioxide disposal in carbonate minerals. Energy 20, 1153-1170. doi:10.1016/0360-5442(95)00071-N

Lackner, K.S., Wilson, R., Ziock, H.-J., 2000. Free-Market Approaches to Controlling Carbon Dioxide Emissions to the Atmosphere. Glob. Warm. Energy Policy 31-46. doi:10.1007/978-1-46151323-0_3

Lawford-Smith, H., Currie, A., 2017. Accelerating the carbon cycle: The ethics of enhanced weathering. Biol. Lett. 13. doi:10.1098/rsbl.2016.0859

Levasseur, A., Brandão, M., Lesage, P., Margni, M., Pennington, D., Clift, R. and Samson, R., 2012. Valuing temporary carbon storage. Nature Climate Change, 2(1), 6-8. doi: 10.1038/nclimate1335

Maggio, G.F., 1997. Inter/Intra-Generational Equity: Current Applications under International Law for Promoting the Sustainable Development of Natural Resources. Buffalo Environ. Law J. 4, 161.

Maréchal, K. and Hecq, W., 2006. Temporary credits: A solution to the potential non-permanence of carbon sequestration in forests? Ecological Economics, 58(4), 699-716. doi:

10.1016/j.ecolecon.2005.08.017

Marland, G., Fruit, K., Sedjo, R., 2001. Accounting for sequestered carbon: The question of permanence. Environ. Sci. Policy 4, 259-268. doi:10.1016/S1462-9011(01)00038-7

Miltenberger, O., Jospe, C., Pittman, J., 2021. The Good Is Never Perfect: Why the Current Flaws of Voluntary Carbon Markets Are Services, Not Barriers to Successful Climate Change Action. Front. Clim. 3, 1-6. doi:10.3389/fclim.2021.686516

Minx, J.C., Lamb, W.F., Callaghan, M.W., Fuss, S., Hilaire, J., Creutzig, F., Amann, T., Beringer, T., De Oliveira Garcia, W., Hartmann, J., Khanna, T., Lenzi, D., Luderer, G., Nemet, G.F., Rogelj, J., Smith, P., Vicente Vicente, J.L., Wilcox, J., Del Mar Zamora Dominguez, M., 2018. Negative emissions - Part 1: Research landscape and synthesis. Environ. Res. Lett. 13. doi:10.1088/17489326/aabf9b

Moura Costa, P., Wilson, C., 2000. An equivalence factor between CO2 avoided emissions and sequestration - Description and application in forestry. Mitig. Adapt. Strateg. Glob. Chang. 5, 51-60. doi:10.1023/A:1009697625521

National Academies of Sciences Engineering and Medicine, 2019. Negative Emissions Technologies and Reliable Sequestration. Negat. Emiss. Technol. Reliab. Sequestration. doi:10.17226/25259

Neeff, T., Ascui, F., 2009. Lessons from carbon markets for designing an effective REDD architecture. Clim. Policy 9, 306-315. doi:10.3763/cpol.2008.0584

Newell, R.G. and Stavins, R.N., 2000. Climate change and forest sinks: factors affecting the costs of carbon sequestration. Journal of environmental economics and management, 40(3), 211-235. doi:10.1006?jeem.1999.1120

OECD, 1975. The Polluter Pays Principle. doi:10.1787/9789264044845-en 
Olhoff, A \& Christensen, JM (eds) 2020, Emissions Gap Report 2020. UNEP DTU Partnership. Available at: https://www.unep.org/emissions-gap-report-2020 [accessed 24 November 2021]

Paris Agreement (2015). Paris Agreement to the United Nations Framework Convention on Climate Change, Dec. 12, 2015, T.I.A.S. No. 16-1104.

Raffensperger, C., 2013. Guardians of Future Generations. Kosmos Journal. Fall-Winter.

Richards, K.R., 2004. A brief overview of carbon sequestration economics and policy. Environmental Management, 33(4), 545-558. doi:10.1007/s00267-003-9111-8

Royal Society, 2009. Geoengineering the climate: Science, governance, and uncertainty.

Ruseva, T., Hedrick, J., Marland, G., Tovar, H., Sabou, C., Besombes, E., 2020. Rethinking standards of permanence for terrestrial and coastal carbon: implications for governance and sustainability. Curr. Opin. Environ. Sustain. 45, 69-77. doi:10.1016/j.cosust.2020.09.009

Scott, V., Haszeldine, R.S., Tett, S.F.B., Oschlies, A., 2015. Fossil fuels in a trillion tonne world. Nat. Clim. Chang. 5, 419-423. doi:10.1038/nclimate2578

Sohngen, B. and Mendelsohn, R., 2003. An optimal control model of forest carbon sequestration. American Journal of Agricultural Economics, 85(2), 448-457. doi:10.1111/1467-8276.00133

SwissRe Institute, 2021. The economics of climate change: no action not an option.

Turner, G., Helmke, E., Tetteh-Wright, T.A., Pitt, C., Oracee, A., Koch, D., Maslin, M., Lewis, S.L., Pye, S., Liebreich, M., 2021. Future Demand, Supply and Prices for Voluntary Carbon Credits Keeping the Balance.

UNFCCC (2005). Report of the Conference of the Parties Serving as the Meeting of the Parties to the Kyoto Protocol on its First Session, Held at Montreal from 28 November to 10 December 2005.

UN General Assembly (1992). United Nations Framework Convention on Climate Change: resolution / adopted by the General Assembly, 20 January 1994, A/RES/48/189, available at: https://www.refworld.org/docid/3b00f2770.html [accessed 4 November 2021]

UN General Assembly (1972). United Nations Conference on the Human Environment, 15 December 1972, A/RES/2994, available at: https://www.refworld.org/docid/3b00f1c840.html [accessed 4 November 2021]

Vaughan, N.E., Lenton, T.M., 2011. A review of climate geoengineering proposals. Clim. Change 109, 745-790. doi:10.1007/s10584-011-0027-7

Wong, P.-H., 2014. Maintenance Required: The Ethics of Geoengineering and Post-Implementation Scenarios. Ethics, Policy, Gov. 17, 186-191. doi:10.1080/21550085.2014.926090

World Bank Group, 2020. State and Trends of Carbon Pricing 2020. Washington, D.C. doi:10.1596/978-1-4648-1435-8

\section{Data Availability Statement}


Data is available from Carbon Plan (https://carbonplan.org/research/cdr-database). The code for producing the base figure can be found at 10.5281/zenodo.5771239. 